\title{
Paulo Cavaleri, 2004, La restauración del Virreinato. Orígenes del nacionalismo territorial argentino, Universidad Nacional de Quilmes, Buenos Aires, Argentina.
}

$\mathrm{E}$ n la historia de la conformación de los pueblos, los sentimientos de identidad que han forjado los nacionalismos ocupan un lugar de singular relevancia. Esto ha sido especialmente cierto en países que en su pasado albergaron vastas conformaciones territoriales y que devinieron por último en países menos extensos. Al respecto, el ejemplo de Argentina es característico. De ello trata el libro que el historiador, abogado y diplomático Paulo Cavaleri presenta ahora. En principio tesis doctoral del autor, en su obra expone el pensamiento que animó a los argentinos del siglo XIX, también del xx, a ver en el antiguo Virreinato del Río de la Plata la proyección en los tiempos independientes de una gran nación argentina. Fue así como se quiso ver, más allá de los límites actuales de la república argentina, un territorio que le habría pertenecido, conformado por Bolivia, Paraguay y Uruguay, también por zonas de Chile, Perú y Brasil. De ahí el título que recibe la obra: La restauración del $V$ irreinato, mismo que indica la imagen manejada por algunos argentinos en cuanto al resurgimiento del espacio territorial ocupado por el Virreinato del Río de la Plata para constituir así una gran nación argentina en los tiempos actuales. Una imagen que — según el autor - se ha mantenido vigente hasta nuestros días y que no es más que la instauración de un mito en el imaginario colectivo de los argentinos.
Indica Cavaleri que la prédica del mito Virreinal comenzó a constituir una pieza clave a finales del siglo XIX para la constitución de la nacionalidad argentina cimentada en la cuestión territorial. En el primer capítulo se remonta a los antecedentes y considera a dos figuras importantes: Juan Manuel de Rosas y Bartolomé Mitre. Bajo la presidencia del primero se efectuó una política tendiente a reconstruir la hegemonía argentina, visible en las relaciones observadas con Uruguay y Paraguay, así como con Brasil. En cuanto al segundo, debe vérsele como historiador, hombre de Estado y diplomático para quien el Virreinato rioplatense había sido una entidad desprovista de verdaderos vínculos $\mathrm{y}$, por tanto, no constituía un proyecto viable de nación.

Aún con ello, la figura más destacada para el autor es la de Vicente Quesada (1830-1913), quien fue pionero en llevar el mito a un plano de mayor proyección. Para Quesada las razones que condujeron a la disolución del Virreinato fueron: el liberalismo emanado del Contrato Social, así como la actuación del Imperio del Brasil, el cual apoyó a los paraguayos y procuró la neutralidad de Uruguay al fracasar en sus empeños de anexión; además Simón Bolívar también contribuyó a ello cuando, animado de un sentimiento antiargentino, vio por la instauración de un gobierno independiente en el Alto Perú. A lo anterior habría que añadir una diplomacia argentina desacertada, incapaz 
de estar a la altura en las negociaciones territoriales, así como la actuación observada por los unionistas argentinos. Como corolario, Quesada observó la aparición de pequeñas naciones, a las cuales consideraba inviables en lo político y en lo económico. Lo que también se reflejaba en las disputas suscitadas en el plano internacional.

El libro está dedicado a estudiar la posición que abanderó Vicente Quesada, por lo cual dos capítulos se encuentran a él referidos. Ha quedado mencionado ya el contenido del primer capítulo en relación con el Virreinato. El segundo refiere a los avatares de su vida que le condujeron al campo de la diplomacia donde intervino en los conflictos internacionales de Argentina. No únicamente realizó este trabajo diplomático, además escribió sobre los derechos de Argentina en la Patagonia. Cavaleri expone también el ideario político que animaba a Quesada, mismo que consta de tres partes: 1) Federalismo y Constitución, 2) Liberalismo, religión y sociedad, y 3) Nacionalismo.

Como parte del mito, Cavaleri indica que éste cuenta con un héroe propio: el rey Carlos III, quien dispuso en 1776 la creación del Virreinato del Río de la Plata. Así Quesada llegó al extremo de considerar dentro del territorio rioplatense a la Patagonia, que no formaba parte de la división administrativa virreinal. A partir de la década de 1880 surge con Quesada desde las páginas de la Nueva Revista de Buenos Aires la concepción de un nacionalismo territorial. En opinión del autor, hay dos factores que explican su surgimiento. El primero es la Campaña del Desierto, comenzada en 1879 y finalizada en 1881 con la firma de un tratado con Chile, por el cual la Patagonia pasó a ser parte del territorio argentino. Con ello, se hacía aparecer la recomposición de la antigua unidad virreinal como algo factible que se traduciría en la reintegración de las distintas partes que se habían separado. El otro factor era el entrever una probable guerra con Chile y Brasil, en esa vinculación estrecha entre guerra y nacionalismo que - como
Cavaleri asevera — ha sido señalada en su momento por Eric Hobsbawm.

En capítulo precedente se mencionan los herederos intelectuales de Quesada. Aquí se considera a Gabriel Carrasco (1854-1908), contemporáneo de Quesada, así como a Ernesto Quesada —nacido en 1858 e hijo de Vicente_- José Juan Biedma, Antonio Bermejo, Joaquín V. González, Ramón Cárcano y Ricardo CailletBois. Apreciamos que se trata de figuras argentinas de los siglos XIX y xx que se desempeñaron como negociadores diplomáticos y que recurrieron al levantamiento de mapas fronterizos para la defensa de la posición argentina. El mito de una nación desmembrada tras la Independencia promovió sentimientos negativos hacia los países vecinos: desconfianza hacia Brasil y Chile; desprecio hacia Paraguay, Bolivia y Uruguay. La visión de este mito es ante todo criollo, pues se hace referencia al surgimiento de la Argentina blanca, basada en la hispanidad, enfrentada al Brasil portugués y mestizo. Como lo que se remarca es la pérdida territorial, entonces emerge un patriotismo negativo fincado en el resentimiento. La rivalidad con Brasil y Chile se inscribe dentro de la política colonialista portuguesa, por una parte, y por los temores de Chile de ver avanzar sobre él a Argentina, una Argentina que además se identifica con un destino grandioso equiparable al de un imperio, por cuanto el Virreinato en sí conllevó esta imagen al administrar también territorios en Africa occidental. El mito ha sido tan vigoroso que ha traspasado cualquier ideología desde la extrema derecha hasta la izquierda considerada "nacionalista". Ha de señalarse, en todo esto, que el discurso apologético del mito ha carecido casi totalmente del tono belicista. Se contenta con advertir la mayor parte de las veces lo que puede ocurrir si no se adopta una actitud más resuelta. Pero es preciso asentar que los nacionalistas territoriales han manejado la imagen de un ejército victorioso frente a una sociedad civil y una diplomacia débiles, lo que conduce a Cavaleri 
a preguntarse si ello no estaría en relación con el surgimiento de una subcultura militar autoritaria en Argentina. He aquí un planteamiento distinto a los desarrollados a lo largo del texto, dirigido por encima de todo a exponer lo que ha sido el mito del Virreinato en los autores argentinos que han abordado el tema.

En este sentido, lo expuesto por Cavaleri ofrece más bien una panorámica de lo que ha constituido el comentado mito del Virreinato entendido dentro de las polémicas territoriales sostenidas por los diplomáticos argentinos, así como una descalificación final del mismo. No hay aquí una mayor interpretación que coloque al mito del Virreinato rioplatense en una perspectiva más amplia. De hecho, el autor ha privilegiado la bibliografía sobre el tema, y apenas ha incluido textos distintos a los del área de estudio. Lo expuesto es útil ante todo para conocer de manera sistemática sobre un tema que quizá hasta ahora no había recibido una debida atención. Por otro lado, sólo se presenta un mapa, impreso en la portada, pues se aclara que por cuestiones editoriales se resolvió excluir los mapas insertos en la tesis doctoral. En todo caso, y aun cuando el mapa que ilustra la portada presta alguna utilidad, habría sido conveniente incluir los restantes.

El tema desenvuelto durante 178 páginas en cuatro capítulos, con una conclusión general, incorpora dos anexos: el primero se centra en realizar una crítica a Vicente Quesada. Ello en sí lo hace aparecer como algo distinto de un anexo, por lo que más bien se le habría podido considerar un capítulo dentro del escrito. El segundo anexo cumple a mayor cabalidad con lo esperado: una carta de Cipriano Quesada dirigida a su hijo Vicente cuando este último parte a Bolivia en septiembre de 1852; incluye las instrucciones del ministro de relaciones Peña al coronel Juan Elías con motivo del viaje del segundo a Bolivia, que en el texto aparece sin fecha. Es de pensar que también otros documentos pudieron haber sido agregados, los cuales hubieran ejercido un mayor interés, quizá, y habrían completado más satisfactoriamente el tema abordado.

Por último, hemos de indicar que el acceder al conocimiento de lo que ha constituido la polémica territorial argentina permite apreciar otras polémicas, en concreto la sostenida por Guatemala en relación con Chiapas y el Soconusco, que nos atañe tan directamente. De principio, hemos de establecer que la cuestión argentina participa de un grado muy elaborado en la fabricación del llamado mito; en el caso guatemalteco, el asunto no trasciende tanto, si bien guarda similitudes al tratarse aquí también de un centro administrativo que gobernaba sobre diversas provincias, separadas del centro rector después de la Independencia. Encontramos aquí como en el caso argentino el resentimiento dirigido hacia quienes son considerados culpables de la desintegración, que en lo tocante a Chiapas y Soconusco se refiere exclusivamente a México. Punto divergente respecto a Argentina, donde el resentimiento se dirige a los países vecinos que formaron parte del Virreinato o hacia aquellos que han sido considerados obstáculo para su reintegración. En el ejemplo guatemalteco no existe ese resentimiento hacia las provincias que constituyeron la Capitanía General y se convirtieron después en repúblicas independientes. Esto nos conduciría a ponderar que en Guatemala ha subsistido más la imagen de una república pequeña que ha perdido territorios y no tanto la de una metrópoli opulenta que sufrió un colapso con la independencia de sus provincias. Quien más se identificó con esta imagen fue Clemente Marroquín Rojas en su Historia de Guatemala, 1971. A su parecer la República Federal de Centroamérica debió llamarse Guatemala, en extensión temporal de la denominación anterior de Reino de Guatemala, en lo que es sin duda un firmísimo deseo de mantener la posición dirigente de la Guatemala de antaño. Pero aunque este pasado colonial permanece en la memoria 
colectiva guatemalteca, su expresión exclusiva referida a Chiapas y Soconusco, sin extenderse a las demás partes constitutivas de la antigua Capitanía, le hace perder ese sentido trascendente que se observa en Argentina. Cuando los guatemaltecos buscan la integración de la América Central, lo hacen más bien desde esa perspectiva regional, alejándose así de una Guatemala que predomine, al menos nominalmente, tal como lo expresara Marroquín.

Así como esa memoria del pasado subsiste en Guatemala, también vemos que se encuentra viva hasta hoy en Argentina, como lo indica Cavaleri, al contrario de lo que se ha llegado a suponer. El autor declara que futuros estudios deberán centrarse en cómo los argentinos se perciben a sí mismos, también la forma en que ven a sus vecinos. La historia intelectual que el autor propone constituye tan sólo una aproximación inicial a esos temas. Sin duda promete ir más allá de lo explorado en este texto, con lo que esos trabajos estarían más propiamente dentro de lo que se considerarían estudios doctorales.

Sergio Nicolás Gutiérrez Cruz

CESMECA-UNICACH 